\title{
Testes informatizados para a avaliação psicológica e educacional
}

\author{
Marlene Alves da Silva ${ }^{1}$ - Universidade São Francisco, Itatiba, Brasil
}

Joly, M. C. R. A. \& Reppold, C. T. (2010). Testes informatizados para a avaliação psicológica e educacional. E-book. São Paulo: Casa do psicólogo.

A tendência do desenvolvimento da informatização da avaliação psicológica é crescente no âmbito internacional e nacional. Essa ferramenta favorece em termos práticos e econômicos a atuação profissional, pois além de dispensar o uso do lápis e papel, a consulta ou aferições de manuais dos testes e a economia de tempo, não há necessidade de digitar dados e principalmente, reduz erros de mensuração, assim como, aproveita de forma plena os avanços da psicometria moderna, garantindo a confiabilidade dos instrumentos, sem afetar a validade e a precisão da avaliação.

Convictas de que nesse novo formato será possível a utilização de testes dinâmicos e complexos que utilizem vários tipos de estímulos, como por exemplo, o visual e o sonoro, o tempo de reação, além de respeitar a heterogeneidade cultural, assim como a possibilidade de explorar toda a tecnologia oferecida em prol de situações específicas para a mensuração dos fenômenos e processos psicológicos do comportamento humano, Joly e Reppold organizam os textos de modo a oferecer um panorama, incentivar a pesquisa e internacionalizar a avaliação psicológica informatizada. Os treze capítulos, escritos por profissionais de Psicologia, referem-se a estudos desenvolvidos por meio de diversos enfoques teóricos e metodológicos, caracterizando como estudos independentes, porém relevantes para a compreensão mais aprofundada na área da avaliação psicológica informatizada.

No capítulo inicial, Maria Cristina Rodrigues Azevedo Joly e Aline Christina Istome apresentam uma análise da literatura sobre como processa a avaliação psicológica e a testagem informatizada no Brasil. Ainda, descrevem os principais desafios e vantagens dessa avaliação. A seguir, conceituam a linguagem oral e oferecem os estudos na área. Assim, expõem a construção e estudos psicométricos de uma Bateria Informatizada de Linguagem Oral (BILO) destinada a avaliar a compreensão da linguagem oral em alunos da educação infantil ao quinto ano do ensino fundamental. Vários estudos foram realizados para adequação da bateria a nossa realidade e no momento

${ }^{1}$ E-mail: alvesmarlene2002@yahoo.com.br encontra-se em sua terceira versão, com a pretensão de realizar pesquisas de validação em vários estados brasileiros.

A neuropsicologia contemporânea têm oferecido avaliação e tratamento, principalmente em relação às operações capazes de regular o processamento de informação pelo cérebro ou as funções executivas, no segundo capítulo, Caroline Tozzi Reppold, Ana Cristina Pedron e Clarissa Marcelli Trentini, mostram uma breve revisão das funções executivas e os componentes dessas funções que podem ser avaliados por meio do Teste de Wisconsin de Classificação de Cartas (WCST) - versão computadorizada, como flexibilidade cognitiva e memória de trabalho, atenção seletiva e controle inibitório, planejamento e seleção de uma determinada ação. Descreveram o teste. Em suas considerações finais ressaltam a importância dessa avaliação e sugerem novas pesquisas.

Cônscios da necessidade de estudos que apresentem a avaliação cognitiva das funções executivas e a sua relevância do desenvolvimento e do uso de testes computadorizados, Alessandra Gotuzo Seabra, Natália Martins Dias e Bruna Tonietti Trevisan trazem, no terceiro capítulo, seis instrumentos para avaliação das funções executivas, a saber, Teste de Stroop Computadorizado, para avaliar a atenção seletiva; Teste de Geração Semântica, para ajuizar o controle inibitório; Teste de Fluência Verbal (FAS), para mensurar a habilidade da fluência verbal; e os instrumentos em desenvolvido, Simon Task, para avaliar o controle inibitório e a memória de trabalho; Teste de Stroop para pré-escolares para aferir o controle inibitório e o Teste de atenção Contínua, também para verificar o controle inibitório e atenção sustentada.

Ana Cristina Pedron e Caroline Tozzi Reppold, considerando a importância de avaliar os processos atencionais e o controle inibitório, descrevem no quarto capítulo, diversos instrumentos desenvolvidos, como, paradigmas que utilizam o efeito Stroop; avalia a dificuldade no processamento de informações simultâneas como significado conflitante; paradigmas ' $g o / n o-g o$ ' e tarefas que medem o tempo de reação com interrupção sinalizada (stroop-signal reaction time - SSRT) que medem as falhas em mecanismos inibitórios. Os vários estudos mostram a importância 
da avaliação neuropsicológica adequada e com instrumentos precisos e válidos. Em suas considerações finais, enfatizam a escassez desses instrumentos, bem como a necessidade de normatização de instrumentos informatizados para amostras nacionais.

No quinto capítulo, Janaína Castro Múñez Carvalho, Daniela Schneider Bakos, Caroline de Oliveira Cardoso, Charles Cotrena, Christian Haag Kristensen e Rochele Paz Fonseca apresentam um instrumento neuropsicológico computadorizado Iowa Gambling Task (IGT) utilizado internacionalmente na avaliação do processo de tomada de decisão diante da incerteza e da ponderação de riscos em população clínica. Os autores descrevem os fundamentos teóricos, o processo de adaptação, interpretação e padronização para a realidade brasileira, bem como os estudos psicométricos realizados com o instrumento. Nas considerações finais e perspectivas futuras, os autores ressaltam a necessidade de realização de estudos com população saudável e clínica neurológica e psiquiátrica, bem com a realização de normas regionalizadas.

No capítulo seguinte, Patrícia Gaspar Mello, Marcelo Montagner Rigoli, Vinícius Guimarães Dornelles, Pedro Antônio Schmidt do Prado-Lima e Christian Haag Kristesen descrevem a tarefa de stroop que objetiva comparar o desempenho da pessoa em três condições, leitura de palavras, nomeação de cores e nomeação das cores nas quais as palavras estivessem escritas e sua relação entre cognição e emoção, bem como a versão computadorizado do stroop emocional que oferece três formas de obter a resposta do indivíduo, por meio do teclado, do mouse e da voz. O programa é de fácil acesso e contém todas as instruções de uso e utilização. Os autores encerram o capítulo salientando que a investigação por meio do stroop emocional possibilita uma melhor compreensão do processamento emocional característico de cada transtorno.

Gerardo Prieto Adánez traz sua contribuição para a compreensão sobre um teste informatizado de visualização espacial, no capítulo sete, apresentando as análises psicométricos do teste. $\mathrm{O}$ autor considera as atitudes espaciais como um conjunto heterogêneo de capacidades que permitem gerar, reter, recordar e transformar imagens visuais de objetos, bem como representar mentalmente e imaginar o ambiente. Essa avaliação pode ser eficiente em arquiteto, engenheiro, taxista, mecânico, controlador de voo, entre outros. O teste de visualização espacial TVZ2006A, em sua versão espanhola e portuguesa, é composto de 20 itens de múltipla escolha para ser respondido no máximo em 30 minutos. As análises psicométricas foram realizadas por meio da Teoria Clássica dos Testes (TCT) e da Teoria de Resposta ao Item (TRI).

Considerando a importância da investigação do desempenho do aluno sobre o funcionamento cognitivo, Maria Cristina Rodrigues Azevedo Joly e Tatiana Cristina Teixeira, apresentam estudos e a construção do teste dinâmico de leitura (TDL) que conta com um pré-teste, módulo instrucional em duas etapas e pós-teste com aplicação sem interrupção entre cada etapa. A avaliação inicial e final é composta pelo Teste de Cloze por Opção - MAL. As autoras descrevem a pesquisa realizada com o TDL e sua correlação com o Teste de Desempenho Escolar (TDE), bem como, a constatação de evidências de validade convergente para o TDL pela relação com outras variáveis e validade de critério por escolaridade e grupos extremos. Destacam a necessidade de avaliadores que dominem conceitos e procedimentos deste tipo de avaliação.

O capítulo nove é o resultado de uma pesquisa que visou avaliar o conhecimento já adquirido da pessoa e o potencial de aprendizagem por meio de um Teste Dinâmico Informatizado para Avaliar o Raciocínio Indutivo (TEDRI). O estudo realizado por Monalisa Muniz Nascimento, Alessandra Gotuzo Seabra, Ricardo Primi e Fabiano Koich Miguel conceituam a avaliação dinâmica, assistida ou interativa, assim como a sua aplicabilidade. Após relatam a construção do TEDRI, sua fundamentação teórica e mencionam os dados psicométricos, destacando-se as análises realizadas sobre a efetividade de mensurar o potencial de aprendizagem que é a finalidade de um teste dinâmico. Finalizam apontando a importância da avaliação dinâmica, TEDRI, em relação à resolução de tarefas com raciocínio indutivo.

Defendendo a necessidade de compreender as emoções em crianças, Carla Alexandra da Silva Moita Minervino, Antonio Roazzi, Maria das Graças Bompastor Borges Dias e Maira Roazzi relatam sobre a competência emocional, compreendida como o conjunto de capacidade que possibilitam reconhecer, compreender e responder de forma coerente às emoções dos outros, além de regular e fazer uso das expressões das próprias emoções; esta entre os três e onze anos e podem ser agrupadas em três fases, externa, mental e reflexiva. Os autores descrevem o processo de construção e validação da versão computadorizada do Teste de Compreensão das Emoções (TEC) ou Test of Emotion Comprehension, a partir da versão original de lápis/papel dos autores Pons e Harris (2000) e Pons, Harris e Rosnay (2005).

No capítulo seguinte, Fabiano Koich Miguel e Ricardo Primi, apresentam estudos para o Teste Informatizado de Percepção de Emoções Primárias 
para Avaliação de Adultos. Inicialmente arrazoam sobre inteligência emocional, conhecida como a capacidade de processamento de informações emocionais de modo a utilizá-las de forma favorável. A seguir descreve a construção do Teste Informatizado de Percepção de Emoções Primárias (PEP) focado na percepção emocional, consistindo em trechos de vídeos de pessoas expressando emoções, assim como os estudos iniciais de validação do teste, por meio de análise de sua estrutura interna e relações com variáveis externas como, os Testes de Raciocínio Abstrato e verbal que compõem a Bateria de Provas de Raciocínio- BPR-5 e a Bateria Fatorial de Personalidade - BFP computadorizados.

No penúltimo capítulo, a avaliação de habilidades sociais é defendida pelos autores, Zilda Aparecida Pereira Del Prette e Almir Del Prette, que relatam os conceitos e premissas da habilidade e competência social. Em seguida, ponderam sobre a importância da avaliação e apresentam os instrumentos de medida, o Inventário de Habilidades Sociais, o Inventário de Habilidades Sociais para Adolescentes e o Inventário Multimídia de Habilidades Sociais para Crianças, a descrição de seus itens, dados psicométricos, normas e apuração computadorizada dos instrumentos. Finalizam enfatizando que essa tecnologia pode ser colocada a serviço do bem-estar e da qualidade de vida dos usuários de serviços psicológicos.

Sobre a autora:

Marlene Alves da Silva é psicóloga e doutoranda do Programa de Pós-Graduação Stricto Sensu em Psicologia da Universidade São Francisco. Bolsista CAPES.
No capítulo final do livro suas organizadoras, Claudette Maria Medeiros Vendramini, Juliana Maximila de Paula Bueno, Flávia Cristina Moreira da Silva e Fernanda Luzia Lopes recorrem ao modelo de créditos parciais na avaliação de uma escala informatizada de atitudes. Esse é um dos modelos proposto por Rasch e tem por objetivo analisar categorias de resposta politômicas e aplica-se a escala de atitudes do tipo Likert e foi escolhido pelas autoras para verificar evidência de validade da versão eletrônica da escala de atitudes e-SATS português. As autoras concluem a análise desse estudo, destacando a existência de poucos instrumentos e estudos relacionados à informatização de testes e escalas informatizadas no Brasil, sugerindo a realização de mais estudos nessa área.

Testes informatizados para a avaliação psicológica $e$ educacional é uma obra que revela a preocupação em compreender a necessidade de realização de estudos com instrumentos psicológicos informatizados. Nesse sentido, trata-se de um livro interessante para profissionais e estudantes que estejam envolvidos com a prática profissional e que compartilham a necessidade de lançar um olhar mais aprofundado sobre o tema. Sua organização permite ao leitor uma série de informações sobre os instrumentos informatizados desenvolvidos e em desenvolvimento no Brasil, o que faz que o livro seja uma excelente fonte de referência. 